\title{
Etnomatemática: metodologia, ferramenta ou, simplesmente, etnorrevolução?
}

\author{
Fernando José Monteiro da Costa ${ }^{1}$
}

\begin{abstract}
Resumo: A aprendizagem não se constitui num movimento linear, simples e que abrace os alunos do mesmo modo. Antes pelo contrário, o processamento é complexo, por vezes, pouco significativo e, quase sempre, desencorajante em algumas disciplinas, como é o caso da matemática. A etnomatemática aparece como uma espécie de porto de abrigo, em relação a uma multidão de alunos que, provavelmente, não tendo dificuldades cognitivas, encontram na matemática uma aridez de pensamento e de práticas escolares. A ancoragem dos novos conhecimentos é uma matéria importante para o processo de ensino e aprendizagem, sendo indispensável que uma norma inclusiva seja o chapéu para todo o universo da aquisição de conhecimentos e de saberes explícitos.
\end{abstract}

Palavras-chave: etnomatemática, teoria das situações didáticas, ensino inclusivo

\section{Ethnomatematics: a methodology, a tool or simply an ethnorevolution?}

\begin{abstract}
Learning is not a linear and simple movement that would embrace students in an equal manner. Rather, the processing is complex, sometimes negligible and almost always discouraging in some subjects such as Math. Ethnomathematics appears as a kind of a safe shelter to a crowd of students that probably do not have cognitive difficulties, but have found in Mathematics a barrenness of thought and school practices. The anchoring of new knowledge is an important issue for the teaching and learning process, making indispensable an inclusion standard as the flag for the whole universe of knowledge acquisition.
\end{abstract}

Key words: Ethno mathematics, theory of didactic situations, inclusive education.

Nomes que não devemos deslembrar

"Foi encarregue, pelo dono de uma grande horta, a dois seus amigos, a recolha de fruta que estava amadurecendo nas fruteiras e que, por tal, era, já,

\footnotetext{
${ }_{1}^{1}$ Doutorado pela Faculdade de Letras da Universidade do Porto. Colaborador com o Centro de Investigação Transdisciplinar, Educação, Cultura, Memória (CITCEM). fjmcosta3@gmail.com
} 
tempo de o fazer. Foi proposto aos seus amigos que, após a recolha e a venda da fruta no mercado tradicional da terra, lhes seria entregue, como compensação do seu trabalho, $1 / 2$ do total negociado. Foi, então, que os seus amigos, lhe responderam: como somos dois, queremos que nos seja entregue 1/4". Estamos, seguramente, perante um caso de etnomatemática e constituiu uma boa metáfora, para iniciarmos a análise do que se trata, afinal, quando falamos em etnomatemática, ou matemática dos lugares.

A Etnomatemática surgiu na década de 1970, pelas mãos de Ubiratan D'Ambrosio, como uma espécie de crítica ao ensino tradicional da matemática e análise da sua aplicação em diversos contextos socioculturais. A palavra surgiu da junção de techné (modo de fazer, técnica), mátema (conviver com a realidade sociocultural, ensinar, explicar) e etno (inserção do homem no meio cultural).

Ubiratan D'Ambrosio é um brasileiro, doutor em matemática, professor emérito em várias universidades brasileiras e, desde cedo preocupado com o ensino da matemática e com o processo pedagógico de abordagem, que deve levar em linha de conta as características dos alunos e dos seus locais culturais, propôs mudanças no currículo da disciplina. É autor de mais de 200 obras, entre livros e artigos científicos e é um dos maiores investigadores de visão holística, em Ciências de Educação.

D'Ambrosio desejava retirar do tabu quotidiano a matemática, que se enredava, como ensino formal e fechado, sendo pressupostos primeiros "a lacuna existente entre muitos conteúdos da matemática do ensino básico e secundário; críticas à inutilidade e à irrelevância, para a formação do educando, de muitos tópicos estudados nas aulas de matemática" (Borges, 2005, p. 144 e segs.). D'Ambrosio fora influenciado por seu pai - Nicolau D'Ambrosio -, mas acabou por encontrar outras formas de se, dele, afastar, utilizando a matemática para, afinal, reforçar o que tinha a comunicar a todo o processo educativo, robustecendo a ideia de que ela teria de estar conectada com o quotidiano das pessoas, caso contrário seria uma espécie de assombro que apavoraria crianças e jovens.

Para além de ter passado pelos EUA, onde desenvolve pesquisas sobre cálculo e teoria das medidas, foi em África, no Mali, que teve a oportunidade de conhecer novas realidades culturais, novos traçados geométricos urbanos, diferentes sistemas de construção, reconhecendo que tudo isso começou a me despertar outras formas de saber, sentir, ser matemático, que não as formas ocidentais e aí está o germe da minha reflexão sobre o que viria a ser a etnomatemática. Aí começa, também, uma reflexão sobre a questão: puxa vida, 
o que adianta eu ter uma tese? (D'Ambrosio, 1990).

Aqui, iniciava-se uma profunda reacção à matemática pura, à necessidade de ela se articular com a vida e encontrar, nesta, o fermento indispensável à sua boa aceitação junto do público, em geral, e, particularmente, junto dos alunos. Esta nova forma de pensar a matemática levou D'Ambrosio a construir, paralelamente, um outro tipo de formação que lhe permitia avaliar as questões fundamentais da educação. E, no Sudão, quando de um congresso sobre Matemática para o Terceiro Mundo, continuava D'Ambrosio a reafirmar uma preocupação com os excluídos, a busca pela paz, relacionando um ensino da matemática com as questões locais da comunidade, sem preocupar-se, unicamente, com as temáticas teóricas da matemática. E não desejava que a matemática servisse, excessivamente, como ferramenta utilizada pela classe dominante, por exemplo, para o fabrico de instrumentos de guerra. Por aqui se vislumbra que D'Ambrosio (1999, p. 12) não conseguia dissociar as questões da etnomatemática, da luta pela paz, sendo que, para ele, "atingir essa paz total é o objectivo maior da educação".

D'Ambrosio foi questionando as razões do ensino da matemática, os problemas que a disciplina arrastava, em termos dos seus conteúdos programáticos, colocando a ênfase, mais do que no ensino, na educação matemática. Afinal, o ensino da matemática será o mesmo para todas as culturas? Será que as crianças e os jovens aprendem a matemática do mesmo modo, sob a mesma metodologia? A compreensão das contribuições da matemática será igual, em termos de valores, para todas as comunidades? Sobre estas considerações, D’Ambrosio (1993, p. 74) afirma que

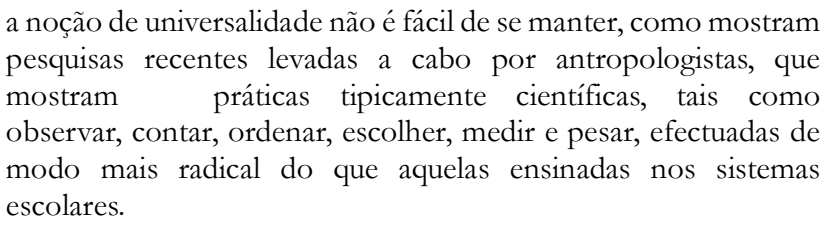
pesquisas recentes levadas a cabo por antropologistas, que mostram práticas tipicamente científicas, tais como observar, contar, ordenar, escolher, medir e pesar, efectuadas de modo mais radical do que aquelas ensinadas nos sistemas escolares.

A estrutura de ensino que ainda hoje se segue, pelo menos em Portugal, é centrada numa transmissão excessiva de conteúdos e na quantidade de conhecimentos apresentados aos alunos, logo desde os primeiros anos escolares. São teoremas, definições de conceitos, equações de matriz complexa, exercícios a fio que procuram, simplesmente, os resultados certos, que, na maioria das vezes, não conduzem à simples resolução de problemas, ou, pelo menos, ao desenvolvimento da capacidade de os solucionar. D'Ambrosio 
propõe, então, que os alunos, por meio da matemática, sejam levados a matematizar situações reais, sejam competentes na construção de teorias adequadas às situações e aos problemas que lhes são próximos. Parece que o quadro real do ensino da matemática evidencia mais o estruturalismo e o formalismo que persistem como a base do ensino geral e menos, o referencialismo a regionalidades, à diversidade cultural. O princípio holístico da educação guia as teorizações de D'Ambrosio, em que o conhecimento é uma tecedura entre diferentes dimensões, como a intuitiva, a sensorial, a emocional e a racional, que não podem ser separadas. Afinal, encontramo-nos perante o dilema de estar com o ensino matemático ou com a educação matemática. Constituem constructos diferentes, modos diversos de abordagem da matemática, que pressupõem utilização de canais de comunicação muito particulares, em cada situação.

Por meio de uma abordagem histórico-cultural-antropológica, D’Ambrosio estava a aproximar-se de uma visão desenvolvimental do ensino da matemática, em que a realidade exerce uma ação sobre o indivíduo, pelo que aquela é a principal fonte do conhecimento, que é gerado "holisticamente e não seguindo qualquer esquema e estruturação disciplinar" (D'Ambrosio, 1999, p. 20). Aproximava-se, como consequência dos seus questionamentos, de um novo conceito que apontava um caminho em direção à transformação crítica das comunidades, na base de um programa de pesquisa e análise das diferentes formas de conhecimento, nas diferentes culturas. Por assim dizer, a etnomatemática deveria ser compreendida como uma ação humana na direção da produção de conhecimento, contextualizada pelas diferentes formas culturais, de diferentes grupos humanos. D'Ambrosio ia ao encontro de uma aprendizagem significativa; aliás, seguia muito de perto Ausubel e aquilo que ele entendia como necessário para que as aprendizagens fossem sólidas e sustentáveis: um ponto de partida onde as novas aquisições fossem ancoradas. D'Ambrosio sustenta que o ambiente, o nosso quotidiano próximo, deve ser o tal ponto e porto de partida.

\section{Literacia, materacia, ou tecnoracia ${ }^{2}$}

Após o final da Segunda Guerra Mundial, generalizou-se um amplo debate sobre o desenvolvimento do homem, não só nos aspetos económicos, mas, sobretudo, sobre que novos modelos educativos deveriam ser ampliados e promovidos. A abordagem interdisciplinar dos saberes constaria de uma nova

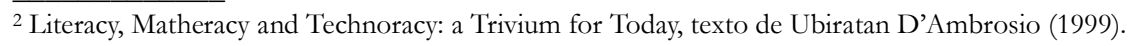


convergência, essencial para a alavancagem de pesquisas, da reformulação de conceitos e, afinal, de uma diferente postura perante o processo de ensino e aprendizagem, pelo que, novas disciplinas vieram à luz do dia, como a etnobotânica, a etnofilosofia, a etnomusicologia, a etnomedicina, etc. As propostas construtivistas ganhavam terreno e crescia a sua influência sobre a educação, surgindo Paulo Freire com as suas propostas para uma escola emancipadora e libertadora. Também a disciplina de matemática começou a sofrer grande processo de análise e de busca de formas de a transformar num saber ao alcance de todos - quer fossem alfabetizados ou não; quer fossem engenheiros, vendedores, calceteiros ou matemáticos profissionais. Retirá-la de um confronto com a realidade seria fragilizá-la, o que, aliás, viria a acontecer, pois a escola não se acanhou perante o facto de ter formalizado, em excesso, as relações matemáticas do quotidiano. Assim, acabou por desenhar um distanciamento entre crianças e a matemática.

Uma das razões daquele distanciamento, que conduz, frequentemente, a insucessos incompreensíveis, seria, precisamente, a falta de perspicácia na abordagem da matemática junto dos mais pequenos, a falta de uma estratégia, de modo que a matemática deixe de parecer tão complexa e elitista, afirmando D’Ambrosio (2003, p. 3) que "os professores precisam aproximar a disciplina do que é espontâneo, deixar a criança à vontade, propor jogos, distribuir balas, objetos, para que o aluno se sinta bem. A criança adquire habilidades para a matemática em casa, no meio em que vive". O conflito surgirá de seguida, quando a escola desvalorizar aqueles conhecimentos e experiências, ignorando que eles, no limite, constituem os subsunçores, essenciais às aprendizagens significativas, de que tanto fala David Ausubel. Portanto, a etnomatemática não pode ser considerada uma metodologia de ensino, que lhe diminuiria as condições para a denúncia de algumas relações simbólicas de poder, que atrapalham os processos de validação e legitimação do saber, e nem permitiria que a prática pedagógica pudesse ser pensada em todas as suas implicações e valências.

Várias discussões analíticas se poderão ter à volta da etnomatemática e de como ela poderia funcionar numa sala de aula. Qual o método a seguir? Como se desenvolve uma unidade na perspetiva da etnomatemática? Que consequências advirão da sua utilização? Como se poderá utilizar um manual escolar? Ou se ele deveria ser substituído por outro tipo de dispositivo? Como sensibilizar os organizadores de manuais escolares para a reconstrução dos seus textos, em face da nova proposta de ação - a etnomatemática como um 
processo de inclusão educativa? Afinal, uma montanha de aspetos se pode colocar, quando, pela frente, temos uma visão distinta da tradicional disciplina matemática. Defende-se que a etnomatemática não constitui um método de ensino, em si mesmo, mas talvez, um plano de ação que revela relações inclusivas entre professores e alunos. Não se pretende, contudo, diferenciar a etnomatemática da chamada matemática, nem tampouco conferir à primeira maior rigor e melhor eficiência. Existe uma arrumação dialógica, uma diferente contextualização, em que

a utilização do quotidiano das compras para ensinar matemática revela práticas apreendidas fora do ambiente escolar, uma verdadeira etnomatemática do comércio. Um importante componente da etnomatemática é possibilitar uma visão crítica da realidade, utilizando instrumentos de natureza matemática (D'Ambrosio, 2001a, p. 23).

Os assuntos a utilizar, que preferimos chamar de saberes, devem constituir-se em assuntos críticos, sejam eles da matemática tradicional ou académica, sejam da etnomatemática residentes na comunidade.

Há uma proximidade, natural e lógica, entre D’Ambrosio e Paulo Freire, entre a etnomatemática e o método de alfabetização do segundo. Paulo Freire não se limita a albafetizar as pessoas, mas, sobretudo, pretende desenvolverlhes uma consciência crítica, numa relação de comunicação, pois sem esta dimensão perde-se a reflexão e, portanto, o diálogo. Também, a pedagogia etnomatemática, porque centrada nos interesses da comunidade, tem por finalidades a prática problematizadora, sob a qual "vão os educandos desenvolvendo o seu poder de captação e de compreensão do mundo" (Freire, 2000, p. 101).

Poder-se-ão inventariar três etapas fundamentais quando se desenvolve uma pedagogia pela etnomatemática. Uma primeira, a da investigação, quando os alunos são confrontados, num processo de mesa-redonda, com as finalidades a atingir, informando dos preceitos que a distinguem do ensino tradicional de matemática. Como segunda etapa, a da tematização, o professor escuta os alunos sobre que temas serão organizados e desenvolvidos, em face da sua realidade. Como terceira fase, a da problematização, as situações de aprendizagem centrar-se-ão sobre as atividades. Há uma particular filosofia neste conceito de etnomatemática, há um primado que é conferido ao aluno e, só depois, aos programas e conteúdos, em que a posição de Ubiratan D’Ambrosio (2001, p.15-33) é clara, afirmando que 
como um Educador Matemático eu me vejo como um educador que tem a Matemática como sua área de competência e seu instrumento de ação, não como um matemático que utiliza a Educação para a divulgação de habilidades e competências matemáticas. Como Educador Matemático procuro utilizar aquilo que aprendi como Matemático para realizar minha missão de Educador. Minha ciência e meu conhecimento estão subordinados ao meu humanismo.

Afinal, retomamos a discussão sobre a urgência em problematizar a Educação Matemática como centro do grande debate, quando nos confrontamos com o insucesso ou o sucesso matemático.

A etnomatemática sustenta-se no facto de o conhecimento ser gerador do saber. Por tal, é no comportamento, na prática que se redefine e se reconstrói o conhecimento, realçando D'Ambrosio (2001a, p. 15-33) que "o processo de aquisição do conhecimento é, portanto, essa relação dialética saber/fazer, impulsionado pela consciência”. Em todos os lugares de todos os tempos, em todas as culturas de todos os tempos, o homem soube adaptar-se e encontrar os modos de conhecer, de saber fazer, pela necessidade de dar resposta a situações distintas, sempre subordinado a um determinado contexto natural, social e cultural. Aprisionando-me das ideias de D'Ambrosio, em todos os tempos e em todas as culturas, Matemática, Artes, Religião, Música, Técnicas, Ciências foram desenvolvidas com a finalidade de explicar, de conhecer, de aprender, de saber/fazer e de predizer (artes divinatórias) o futuro. Todas aparecem, num primeiro estágio da história da humanidade e da vida de cada um de nós, indistinguíveis como formas de conhecimento (D'Ambrosio, 2001a, p. 15-33).

Não se devem desligar os conhecimentos matemáticos de outros saberes, correndo-se o risco de transformar a matemática numa mera técnica ou conjunto de habilidades. No passado, estudava-se matemática junto da astronomia e da música, pelas relações próximas que existem. A própria geometria foi tão importante para os antigos egípcios, pela necessidade de voltar a medir os terrenos, sempre que o Nilo aumentava o seu caudal e inundava os terrenos férteis, ou então, como os índios contavam o tempo por luas (aquele lugar fica a tantas luas daqui), o que reflete a praticabilidade que a geometria tinha para eles. A geometria do povo, dos balões e dos papagaios é colorida, mas a geometria teórica abandonou a cor. E é, precisamente, numa aliança entre Arte e Geometria que a cor se estabelece como mediadora do sentido artístico. Cor, geometria, música, aritmética estão hoje estreitamente 
ligadas, numa aliança próxima, que a educação deveria saber, por um lado, conhecer e, por outro, consolidar. Mas também as medidas por comparação (para medir, comparamos a distância com outra que denominamos medida padrão) ou as medições transversais e longitudinais a partir de estruturas anatómicas; ou, mesmo, os procedimentos de contagem realizada por horticultores, que configuram processos de quantificação muito diferentes dos matemáticos, podem confirmar do interesse da etnomatemática como processo de proximidade ao meio cultural do indivíduo.

Estaremos, assim, confrontados com um novo e diferente universo de intervenção, no âmbito da Etnoeducação. D’Ambrosio está atento e defende "a adoção de uma nova postura educacional, a busca de um novo paradigma de educação que substitua o já desgastado ensino-aprendizagem, que é baseado numa relação obsoleta de causa-efeito" (D'Ambrosio, 2001a, p. 15-33). Procura-se, assim, um diferente sentido educacional, mais estimulante, mais criativo, mais desinibidor, que conduza a novas formas de relações e aprendizagens interculturais. Para D'Ambrosio (2001a, p.15-33), a etnomatemática "é uma disciplina que elimina as desigualdades que preserva a diversidade". A narrativa da etnomatemática deverá ser escrita a partir da diversidade, que possibilitará a inclusão, a tolerância e o respeito pelos processos de aculturação, o que, desta forma, promoverá a consciência da identidade e da memória coletiva, sem ficar, portanto, no mero direito ao conhecimento acumulado. Então, confrontar-nos-emos com o compromisso de construir uma visão mais alargada sobre o mundo em que nos inserimos, permitindo que os alunos alonguem, igualmente, o seu espetro de saber, indo mais além da escola e do seu conhecimento transmitido por uma metodologia gasta e enganadora, muitas das vezes. A escola é apenas um dos lugares onde se pode aprender.

Pensamentos e atos, perceções e ações são o modo de podermos modificar o nosso entorno ou, pelo menos, melhor compreendê-lo na sua complexidade, de modo que consigamos dar solução a problemas do quotidiano, que envolvem muitos aspetos que não se concentram somente na matemática. Todos os povos do mundo se dedicaram a matematizar os seus problemas, mas no sentido de os resolver, e não por uma mera prática científica ou de habilidade instrutiva. A etnomatemática pode contribuir, de modo decisivo, para a melhor compreensão do mundo, tornando-o mais humanizado e menos tecnocratizado. Vergani (2000. p. 33) sustenta que o pensamento etnomatemático se encontra numa direta conexão com a ordem cultural das 
sociedades, pois “a matemática, modelizando situações ou estruturando problemas, faz parte do diálogo vital que o homem teve com o meio. A educação etnomatemática é um processo antropológico". Mas não se pense que a etnomatemática e a matemática tradicional estão afastadas uma da outra ou não podem completar-se. Erro crasso, pois, se a primeira descreve os conhecimentos a partir das experiências locais, a segunda, por meio da didática, está obrigada a transmiti-los em novas condições, e isso conduz o indivíduo a um legítimo compromisso responsável com a sua cultura.

Devemos centrar-nos um pouco num paradoxo existente quando se ensina matemática ou outra qualquer disciplina. Mas a matemática, como o sabemos, exige uma sequência lógica de aprendizagens, de modo se possa compreender o sequente, porque conhecemos, já, o antecedente. Aqui, iniciase um problema, que poderemos definir como a Regra IPS ${ }^{3}$, que diz que deve existir um conjunto de termos e de sintaxe para que se compreenda uma determinada mensagem. Ora, tudo que seja necessário à aquisição de um conhecimento que se deseja ensinar deverá ser ensinado anteriormente, como facilmente se compreenderá. Daqui, se poderia remeter a análise para a aprendizagem significativa de David Ausubel, em que se necessita da existência de subsunçores, nos quais se ancorem os novos conhecimentos. Mas os professores de matemática apresentam muitos dos seus problemas numa ordem axiomática, sem possibilidade de os alunos conhecerem os seus antecedentes ou perceberem o seu uso e interesse. É, afinal, uma aprendizagem sem significação e de alto custo no futuro do aluno e na qualidade de sua aprendizagem. Há, por vezes, mesmo em matemática, um processo de memorização excessiva, que não garante a compreensão total do problema e nem corresponde aos processos históricos da descoberta dos axiomas e postulados, das proposições primitivas, afinal, conhecidas universalmente e aceites sem demonstrações.

Aquilo que poderemos chamar de macrodidática não é mais do que alguma prepotência da matemática em impor resultados ou conceitos que conduzem, em muitas das ocasiões, a vazios de compreensão. É o que pode acontecer, quando, por exemplo, modificamos o nome de figuras geométricas, sem uma ordem racional plausível, como sucede quando chamamos triângulo e, de repente, chamamos quadrado à figura seguinte, quando seria mais lógico que primeiro definíssemos qual o qualificativo a usar, se o número de lados, se o número de ângulos e, somente depois, iniciássemos a denominação, evitando a

${ }^{3}$ Informação prévia suficiente 
sequência instável de triângulo, quadrado e pentágono. Houve situações que puderam ser consideradas na sua irregularidade, mas jamais corrigidas, como o que acontece com a contagem em língua francesa, quando, entre 70 e 90 existe um vazio, porque se designa cinquante, soixante, mas não septante, buitante e neufante, como na linguagem condorcetiana. Curiosamente, a Convenção decidiu suprimir esta irregularidade em 1794, mas nunca nenhum governo ousou considerar aquela alteração. É aqui que a etnomatemática deve intervir, apelando para os conhecimentos em sede de uma determinada cultura e em benefício de uma população, na sua plena participação naquela. A etnomatemática é um projecto crítico da sociedade e do modo como esta se prepara e prepara os seus cidadãos para a (re)interpretação da realidade circundante. Não pouco frequentemente, se escuta que a matemática, esta ou aquela disciplina, são matérias essenciais, estruturantes do pensamento do indivíduo. Como se elas todas, no cruzamento das suas ideias, na tessitura das suas concepções, não constituíssem base primordial do desenvolvimento global do indivíduo. Mas a escola que queremos apelidar de tradicional deseja manter esta situação, atribuindo mais relevo à língua e à metamática, como matérias estruturantes do pensamento, esquecendo-se que tal não corresponde aos processos históricos e mentais das diferentes sociedades. A disciplinarização excessiva dos conteúdos conduz a este estado de sítio, caótico e insustentável, sob o ponto de vista de uma aprendizagem consolidada.

Se a matemática se transmite por meio de códigos e símbolos particulares, possui uma estrutura própria que a distingue de outros saberes, identifica-se como um universo singular de interpretação da realidade, então, estaremos perante uma linguagem, porque expressa, comunica e decifra. Poderemos, então, porque de uma linguagem se trata, questionar se nos encontramos diante de um mecanismo que pode distorcer a realidade, pode manipulá-la de acordo com interesses terceiros, levando o indivíduo a reorganizar a sua, própria, existência? Poderá a matemática formatar a realidade, controlando-a e regulando-a nos seus principais momentos e actividades, como apresentar estatísticas, taxas de juro, comissões e percentagens? Com frequência se utilizam dados estatísticos para a justificação de determinadas particularidades, a bel prazer do processador, dados que se confrontam, no imediato, na alteração da realidade. Temos, então, que o poder formatador da matemática "supõe a submissão da realidade a modelos matemáticos pré-estabelecidos, que dão suporte a decisões e moldam nosso cotidiano" (Milanezi, 2007, p. 42). 
Por isso, não se dispensará algum conhecimento, nem se o fragilizará, perante outro que se considere mais importante ou mais prepotente, tome o nome de Matemática informal, ou espontânea, ou oprimida, on escondida, ou congelada, popular ou profissional. A etnomatemática pode, assim, ser considerada um vigoroso facilitador da comunicação, mas também uma pedagogia entrelaçadora, entre a matemática escolar e os conhecimentos matemáticos, como partes, de meios não escolares.

\section{Etnomatemática e um caso de inclusão educativa}

Tem-se, então, que a matemática tradicional é uma matéria aborrecida, somente porque os alunos não a compreendem em toda a sua dimensão e é transmitida por um processo hermético e desligado da realidade. Assim, eles perdem o interesse e diabolizam-na, frequentemente. Os professores têm tentado utilizar métodos diferenciados de abordagem, relacionando os exercícios matemáticos com a realidade, procurando integrar o jogo como pedagogia ativa e mais atraente. Mas existe um esquecimento insustentável, que se prende com o facto de desconsiderarmos que a criança, antes de entrar para a escola, possui, já, conhecimentos empíricos matemáticos: já conhece o dinheiro, já faz compras na mercearia local, leva dinheiro e traz trocos, realiza pequenas operações matemáticas quando troca conjuntos de rebuçados e organiza série de cromos. Existe um elenco apertado de contraindicações, como proibição de contar pelos dedos, consulta de tabuadas ou indispensabilidade de fazer contas de memória. Isso pode tolher a criança e encostá-la à insegurança ou à vergonha. E aqui a escola, mais uma vez, deveria tomar a dianteira e processar a organização de pequenos projetos que mantivessem ativos aqueles princípios e práticas, conferindo-lhes, agora, consistência científica. A economia escolar, matéria afastada dos conteúdos escolares, deveria ser assumida como essencial para a compreensão da matemática e do seu jogo social, integrando, senão a formalidade do currículo, pelo menos a utilidade em tempos disponíveis.

A etnomatemática pretende, acima de tudo, não desconsiderar os saberes de alguém ou de algum grupo e ampliar, dessa forma, o conceito de matemática, agora, integrado numa determinada cultura. O meio circundante passa a ser um local de ensino e aprendizagem, onde os saberes se encontram e onde tudo se pode construir por um processo racional de comparação. E, se esse modo de agir se iniciar desde muito cedo, então, os alunos estarão preparados para começar a sua longa viagem por veredas mais complexas, mas agora mais 
atraentes e úteis. E isto porque o insucesso na disciplina de matemática começa muito cedo, mesmo antes dos 10 anos de idade, com taxas de fracasso a rondar os 50\%, por exemplo, nas provas de aferição referentes ao ano de 2012.

Contudo, não se poderá esquecer que existem vozes contrárias, críticas à etnomatemática, que são de considerar, e algumas delas se centram no facto de nos termos escolarizado dentro da matemática ocidental convencional e agora nos questionamos como podemo-nos adaptar a outros padrões paradigmáticos. Taylor critica a etnomatemática pelo facto de esta se preocupar, fundamentalmente, pelo ato de ensinar e se esquecer da cognição. Esta parecenos constituir uma falácia, pois o procedimento é único, mas bipolar, quer dizer, é um ato que se inscreve num processamento entre o ensino e a aprendizagem. $\mathrm{E}$, se o conhecimento social do aluno é importante, mais relevante se torna o processo de educação global, a que a etnomatemática deita mão. Muitos dos conceitos matemáticos ocidentais se encontram desenraizados de um sistema cultural, e aí, podem assinalar-se motivos para as diferenças culturais que existem entre muitas comunidades, sejam elas ocidentalizadas ou em vias de ocidentalização, como é o facto de a unidade para muitas comunidades ser dois e não um, como chegou até nós através dos gregos; ou mesmo quando, para alguns horticultores, a unidade significa um molho de 5 coisas. Aqui, imperam noções de paridade, acasalamento, núcleo familiar, de facilitação da tarefa, que contrariam o nosso ver ocidental.

Mas a questão volta sempre ao início, à consideração da importância do meio sociocultural envolvente e do repositório de influências e de saberes que ele contém. Com o progressivo desenvolvimento tecnológico, com as novas formas de fazer e de ser perante os mais recentes artefactos, o processo de ensino e aprendizagem exige, de todos, circunstâncias mais inovadoras de construção dos conhecimentos. A matemática informal liga-se à diversidade cultural e, nesta, encontra múltiplas conceções de valorização e reconhecimento, para a sua operação. Naquela informalidade, a abordagem etnomatemática contempla um vasto campo de ação, para a coleta de saberes formais e informais, o que validará a relevância dos saberes matemáticos obtidos a partir das práticas do quotidiano. A perspetiva d'ambrosiana dá relevo à matematização dos saberes culturais, valorizando-os e aperfeiçoando-os com algum conhecimento matemático formal. 
Nesse sentido, o estudo da Numerofonia de Sergio Aschero ${ }^{4}$ conduz-nos ao centro nervoso da etnomatemática, dando relevo aos conhecimentos já adquiridos, muitos deles obtidos a partir do meio físico e biológico envolvente. Aschero debate-se contra o excesso de códigos, símbolos, notas à margem, de que a notação musical tradicional está prenhe, mais complicando do que facilitando a leitura e a interpretação de textos musicais. Ele não está a desvalorizar o ensino formal da música; antes pelo contrário, está a permitir que os $95 \%$ de pessoas que não conseguem operar no sistema tradicional o possam fazer, agora, de um modo mais criativo e significativo, utilizando os conhecimentos, muitas das vezes empíricos, que elas têm sobre o fenómeno musical. Afinal, não se está mais do que a ampliar a nossa visão sobre a diversidade cultural e, portanto, musical, revelando-se novos e diferenciados caminhos de aprendizagem. Mas também, e porque o sistema numerofónico parte da utilização da geometria e da aritmética - saberes que os envolvidos adquiriram, primeiramente, através das suas comunidades -, estamos diante de um autêntico princípio de aplicação da etnomatemática. Os desenhos espaciais, a medida, o tempo e o espaço, os modos específicos de raciocínio e dedução, estão presentes na numerofonia, mas sob um olhar inclusivo e distante dos princípios fechados, construtivistas e teóricos da matemática formal.

Sergio Aschero parte, primeiramente, de postulados essenciais ${ }^{5}$, relacionando som e imagem, em que uma imagem (uma geometria) representa a duração; a cor (cromáfono de Aschero a partir das cores do arco-íris) representa a altura do som; e o tamanho indica a intensidade. Estes são os pressupostos avaliadores do sistema de Aschero. Confrontamo-nos, de imediato, com uma perspetiva trandisciplinar (sugerida pelos processos educativos) que, sob o ponto de vista antropológico, é a essência da educação, transcendendo, portanto, o nível disciplinar. Aqui, a etnomatemática será aproveitada para dar algum suporte teórico, resolvendo o aspeto da desmotivação e o frágil desempenho dos alunos. Estes, que conhecem, no imediato, a noção de cor, porque ela existe na natureza e com ela contactam no quotidiano; que têm a noção de forma, porque no seu envolvente a concebem a partir de uma flor, de um objeto, ou têm, dela, consciência, porque conhecem o que é uma geometria simples, a partir de um quadrado, ou de um círculo; que

${ }^{4}$ Sergio Aschero é um musicólogo e matemático argentino, criador de um inovador sistema de codificação musical, de nome Numerofonia, em que utiliza as cores, a aritmética e a geometria, abdicando de toda a simbologia da notação musical tradicional.

${ }^{5}$ Não cabe neste artigo a descrição completa do sistema numerofónico de Aschero.

Zetetiké - FE/Unicamp - v. 22, n. 42 - jul/dez-2014 
com o tamanho se confrontam regularmente, observando a realidade que os cerca, estão, assim, preparados para iniciar e compreender a escrita, a produção ou a interpretação de textos musicais, independentemente da sua dificuldade. Trata-se de um processo científico, aquele em que se baseia a Numerofonia de Aschero; portanto, desde logo, a aprendizagem significativa e sustentável está garantida, porque os alunos começam a dilatar os seus conhecimentos sobre ótica, acústica, geometria, aritmética, biologia, história e, claro, sobre música, o que, de outro modo, seria complicado fazer e muito desinteressante para os alunos. A proposta de trabalho baseia-se, então, no reconhecimento e na identificação das construções conceptuais adquiridas pelos alunos.

A Numerofonia, que se trata de um simples sistema de codificação musical, de base científica, como o dissemos atrás, parte do conhecimento prévio dos alunos, que, frequentemente, é desconsiderado pela escola. Subestima-se, pura e simplesmente, a experiência pessoal. E aqui, a experiência pessoal passa a ser determinante para o exercício numerofónico, pois bastará ao aluno conhecer o valor da unidade (um quadrado, uma flor, um círculo), identificar a sequência de cores (o arco-íris facilitará aquele conhecimento) e aplicar o princípio de que o tamanho representa a intensidade e tem um significado lógico - tudo que é maior será mais intenso e o menor representará o menos intenso; ou, se preferirmos a nomenclatura musical, obteremos o forte e o piano, respetivamente. Para além do mais, é seguir, agora, a norma da escrita musical, adequando os princípios indicados. As vantagens serão de imediato identificadas, os alunos sentirão mais facilidade na aprendizagem musical, agora libertos de toda a tralha da notação tradicional; cimentarão as noções básicas de geometria; saberão melhor aplicar os números inteiros e fraccionários, em termos dos tempos musicais; conhecerão melhor a formação da cor e a constituição do arco-íris, para além de todos os outros saberes complementares, como a noção de comprimento de onda, frequência do som e da cor, propagação do som, divisão geométrica do espaço, etc. Aschero costuma afirmar: queremos crer por graça, mas também, por dever de ofício, que a Numerofonia é o único sistema musical que nos permitirá tocar um jardim, um conjunto de flores ou o nascer e o pôr do sol. E disso não há dúvidas, a avaliar pelo longo trabalho que Sergio Aschero tem produzido, desde 1965, ano em que iniciou as pesquisas que o haviam de levar ao ano de 2008, momento em que estabilizou e fechou o sistema numerofónico ${ }^{6}$.

${ }^{6}$ Sergio Aschero tem a sua teoria, A Numerofonia, dispersa por variados artigos, comentários, palestras que, facilmente, poderão ser encontrados nos muitos sites e blogs na internet.

Zetetiké - FE/Unicamp - v. 22, n. 42 - jul/dez-2014 
Esta relação dialógica que deve existir com o meio envolvente, vai confrontar-nos com a circunstância de que os conteúdos tradicionais têm uma importância secundária no todo educativo e instrutivo e relevam para primeiro plano aqueles que se constituam em substâncias críticas, contrapondo-se, então, à descontextualização, porque esta é falsa e falsificadora. O método comparativo e a contextualização são o suporte do sistema numerofónico, onde se encontra a natureza, como o mar revolto das ideias criativas, eliminando o princípio de excluir para, depois, incluir. A busca na natureza dos materiais necessários para a produção musical (padrões geométricos, formas, cores e tamanhos) contraria, seriamente, um processo dinâmico de aprendizagem que se deverá nortear por uma ida a campo, para a pesquisa e a descoberta da essencialidade que fez construir o homem.

Estaremos diante de uma extraordinária ferramenta de aprendizagem, quando falamos de etnomatemática? Poderemos, por meio dela, melhor contextualizar o ensino? Será que afastamos, de vez, o modo mecanicista como utilizamos a matemática? Resolveremos o problema daqueles que detestam a matemática? Ou iniciaremos a longa viagem de excitação pelos números e pelas formas? Um longo campo de pesquisa se alinha diante de nós, queiram os investigadores investir na alteração de paradigmas estafados, quer dizer, procurar uma nova relação entre as coisas, dar prioridade a diferentes modelos de análise e potenciar as novas descobertas e experiências. O desenvolvimento da capacidade de argumentar, de reformular, de ouvir, de encorajar os alunos a solucionar problemas, de formular conjeturas, é, seguramente, o superior objetivo do processo educativo, pois, também deste modo, estamos a assegurar a evolução da aprendizagem e da construção de cidadania. Afinal, encontramonos no verdadeiro universo da Etnoeducação.

\section{Referências}

BORGES, R. A. S. A matemática moderna no Brasil: as primeiras experiências e proposta de seu ensino. Dissertação (Mestrado) - Pontifícia Universidade Católica de São Paulo, São Paulo, 2005.

D’AMBROSIO, U. A educação matemática e etnomatemática. Teoria e Prática da Educação, Maringá - PR, vol. 4, nº 8, jun. p. 15-33, 2001a.

D’AMBROSIO, U. Educação para uma sociedade em transição. Campinas: Papirus, 1999.

D’AMBROSIO, U. Etnomatemática. São Paulo: Ática, 1990.

D’AMBROSIO, U. Etnomatemática. Arte ou técnica de explicar e conhecer. 2. ed. São Paulo: Atual, 1993.

D’AMBROSIO, U. Etnomatemática - elo entre as tradições e a modernidade. Belo Horizonte: Autêntica, 2001b.

DIÁRIO DO GRANDE ABC. Etnomatemática. Diário na Escola. Santo André, 31 out. 2003,

$$
\text { Zetetiké - FE/Unicamp - v. 22, n. } 42 \text { - jul/dez-2014 }
$$


p. 3. Disponível em: http://etnomatematica.org/articulos/boletin.pdf. Acesso em: 9 out. 2012. FREIRE, P. Pedagogia do oprimido. 29. ed. Rio de Janeiro: Paz e Terra, 2000 [1970].

MILANEZI, P. L. O poder formatador da Matemática, a ideologia da certeza e a Educação Matemática: constatações a partir de uma experiência. In: ARAÚJO, J. (Org.). Educação matemática crítica: reflexões e diálogos. Belo Horizonte: Argumentum, 2007. p. 25-38.

VERGANI, T. Educação Etnomatemática: o que é? Lisboa: Pandora Edições, 2000.

Submetido em 13/12/2012

Aprovado em 01/03/2013 